\begin{tabular}{|c|c|}
\hline \multirow{2}{*}{ MAGNA } & Research Article \\
MEDIKA & Berkala Ilmiah Kedokteran dan Kesehatan \\
& Journal Page: https://jurnal.unimus.ac.id/index.php/APKKM \\
\hline
\end{tabular}

\title{
The Relationship Between The Level of Mother's Breastfeeding Knowledge With Exclusive Breastfeeding Practice in The Center of Public Health Kenjeran
}

\author{
Zida Shofy Husnayain ${ }^{1}$, Annisa Nurida ${ }^{2}$, Uning Marlina ${ }^{3}$, Kartika Prahasanti $^{4}$ \\ 123) Fakultas Kedokteran Universitas Muhammadiyah Surabaya
}

\begin{tabular}{l}
\hline \multicolumn{1}{c}{ Article Info } \\
\hline Article history: \\
Received 28 Nopember 2020 \\
Revised 24 Januari 2021 \\
Accepted 24 January 2021 \\
Available online 01 February 2021 \\
\hline Keywords: \\
Breastfeeding; Exclusive; Breast \\
Milk; Knowledge \\
\hline Correspondence: \\
zidashofy5@gmail.com \\
\hline
\end{tabular}

How to cite this article:

1. Husnayain ZS, Nurida A, Marlina U, Prahasanti K. The Relationship Between The Level of Knowledge of Mothers About Breastfeeding With Exclusive Breastfeeding in The Center of Public Health Kenjeran. MAGNA MEDIKA Berk Ilm Kedokt dan Kesehat. 2021; $8(1): 1-7$

\begin{abstract}
Background: Exclusive breastfeeding is giving breast milk exclusively from newborns to 6 months of age without giving any food. Exclusive breastfeeding is essential for optimal baby growth and development, contains various essential nutrients for babies. In 2018 the coverage of exclusive breastfeeding in Indonesia still reached $65.16 \%$, and the coverage of breastfeeding in East Java itself was still below the target of $76.98 \%$. The low level of exclusive breastfeeding is still a problem because it can cause the baby's immune system to become lower, indigestion and illness risk in the baby is more generous to target.

Objective: To determine the relationship between mothers' level of knowledge about breastfeeding and exclusive breastfeeding at Kenjeran Primary Health Center.

Methods: This observational analytic study with a cross-sectional study design. The sampling technique was using the purposive sampling technique. Respondents in this study were mothers who had babies 6-24 months. The data collection process was directly asked through a questionnaire and analyzed using the contingency coefficient test.

Results: This study involved 51 mothers who gave exclusive breastfeeding and 51 mothers who did not. The results showed that most of the respondents who breastfed and did not have the right knowledge level. Based on the contingency coefficient test results, it was found that there was no relationship between the level of mother's knowledge about breast milk to give exclusive breastfeeding at the Kenjeran Primary Health Center (the value of $\mathrm{p}=0.251$ ).

Conclusion: There is no relationship between mothers' level of knowledge about breastfeeding and exclusive breastfeeding at the Kenjeran Primary Health Center.
\end{abstract}




\section{PENDAHULUAN}

ASI eksklusif adalah memberi Air Susu Ibu secara eksklusif dari bayi baru lahir hingga berusia 6 bulan tanpa memberikan makanan apapun. Pemberian ASI eksklusif penting untuk tumbuh kembang bayi yang optimal baik fisik, mental dan kecerdasan $^{(1)}$. Tahun 2018 angka cakupan ASI eksklusif di Indonesia masih mencapai 65,16\% dan cakupan ASI di Jawa Timur sendiri masih dibawah target yaitu $76,98 \% \%^{(2)}$. Pemberian ASI eksklusif yang rendah merupakan salah satu pemicu rendahnya status gizi bayi dan balita ${ }^{(3)}$. Dampak rendahnya pemberian ASI eksklusif pada bayi dapat berupa kekebalan tubuhnya menjadi lebih rendah, gangguan pencernaan, dan resiko sakit pada bayi lebih besar ${ }^{(4)}$.

Salah satu factor yang mempengaruhi keberhasilan ASI eksklusif yaitu adanya peran petugas kesehatan yang baik, pengetahuan ibu yang baik, dukungan keluarga, dan cara penyimpanan ASI untuk ibu yang bekerja ${ }^{(5)}$. Penelitian Rachmaniah menyebutkan bahwa faktor pengetahuan ibu sangat berpengaruh terhadap pemberian ASI eksklusif ${ }^{()}$. Hal ini juga sesuai dengan penelitian Nurkhayati yang menyatakan bahwa semakin tinggi pengetahuan ibu semakin tinggi pula motivasi ibu untuk memberikan ASI eksklusif. Penelitian Nurkhayati tersebut subjek penelitian memiliki pengetahuan sedang dengan kategori subjek sudah mengetahui apa yang dimaksud ASI eksklusif, kandungan gizi, manfaat, waktu pemberian MP-ASI, teknik menyusui yang baik dan benar, cara mengatasi masalah dalam menyusui dan mitos dalam hal menyusui ${ }^{(7)}$.

Penelitian ini bertujuan untuk mengetahui 1) hubungan antara tingkat pengetahuan ibu tentang ASI dengan pemberian ASI eksklusif di puskesmas kenjeran. 2) Mengetahui tingkat pengetahuan ibu tentang ASI Eksklusif apakah baik, cukup, atau kurang. 3) Mengetahui persentase ibu yang memberikan ASI Eksklusif 4) Mengetahui faktor pengetahuan yang paling kuat pada pemberian ASI Eksklusif. Manfaat dalam penelitian ini diharapkan dapat menambah wawasan ilmu tentang hubungan antara tingkat pengetahuan ibu tentang ASI dengan pemberian ASI eksklusif. Serta dapat memberikan informasi kepada petugas kesehatan dan penelitian selanjutnya sebagai bahan kajian.

\section{METODE PENELITIAN}

Jenis penelitian ini adalah analitik observasional dengan rancangan penelitian yang digunakan adalah cross sectional. Populasi dalam penelitian ini adalah ibu yang mempunyai balita di puskesmas kenjeran. Teknik pengambilan sampel menggunakan teknik purposive sampling dengan kriteria inklusi yaitu ibu yang mempunyai anak 624 bulan, bersedia menjadi subjek penelitian, dan ibu yang bisa membaca dan menulis.

Variable bebas dalam penelitian ini yaitu pengetahuan ibu tentang pemberian ASI sedangkan variable terikat yang digunakan yaitu pemberian ASI eksklusif. Pengetahuan sendiri 
akan dibagi menjadi tiga kategori yaitu kurang, cukup, dan baik. Pemberian ASI eksklusif dibagi menjadi dua yaitu ibu yang tidak memberikan ASI eksklusif dan ibu yang memberikan ASI eksklusif. Proses pengambilan data ditanyakan secara langsung melalui kuesioner.

Analisis data menggunakan analisis univariat dan bivariat. Analisa univariat yaitu dengan melihat sebaran data dari variabel terikat, variabel bebas, dan karasteristik responden. Analisa data bivariat digunakan untuk melihat hubungan antara dua variabel dengan menggunakan uji koefisien kontingensi. Besar sampel minimum yang dihitung menggunakan rumus lameshow sebesar 48 responden.

\section{HASIL}

Data dalam penelitian ini diambil dari hasil pengisian kuesioner oleh responden. Jumlah sampel yang digunakan dalam penelitian ini yaitu 102 dengan proporsi ibu yang memberikan ASI eksklusif 51 responden dan 51 ibu yang tidak memberikan ASI eksklusif.

\section{Analisis Univariat}

Analisis univariat dilihat dari karakteristik responden yang meliputi usia ibu, pendidikan ibu, pekerjaan ibu, penghasilan ibu, jumlah anak, dan tingkat pengetahuan. Secara deskriptif karakteristik responden dapat dilihat pada tabel berikut.

Tabel 1. Karakteristik Responden

\begin{tabular}{|c|c|c|c|c|}
\hline & Kategori & Jumlah (n) & Presentase (\%) & $P_{\text {value }}$ \\
\hline \multirow{4}{*}{ Usia } & $\leq 18$ & 1 & $0,1 \%$ & \multirow{4}{*}{0,000} \\
\hline & $19-35$ & 86 & $84,3 \%$ & \\
\hline & $>35$ & 15 & 14,7 & \\
\hline & Total & 102 & $100 \%$ & \\
\hline \multirow{4}{*}{ Pendidikan } & Cukup & 33 & $32,4 \%$ & \multirow{3}{*}{0,000} \\
\hline & Tinggi & 69 & $67,6 \%$ & \\
\hline & Total & 102 & $100 \%$ & \\
\hline & Bekerja & 15 & $14,7 \%$ & \multirow{3}{*}{0,000} \\
\hline \multirow[t]{3}{*}{ Status pekerjaan } & Tidak bekerja & 87 & $85,3 \%$ & \\
\hline & Total & 102 & $100 \%$ & \\
\hline & $<\mathrm{UMR}$ & 76 & $74,5 \%$ & \multirow{3}{*}{0,000} \\
\hline \multirow{3}{*}{ Tingkat penghasilan } & $\geq$ UMR & 26 & $25,5 \%$ & \\
\hline & Total & 102 & $100 \%$ & \\
\hline & Primipara & 38 & $37,3 \%$ & \multirow{3}{*}{0,010} \\
\hline \multirow[t]{2}{*}{ Jumlah anak } & Multipara & 64 & $62,7 \%$ & \\
\hline & Total & 102 & $100 \%$ & \\
\hline
\end{tabular}

Berdasarkan tabel 1, didapatkan adanya perbedaan yang signifikan usia, pendidikan, status pekerjaan, tingkat penghasilan, dan jumlah anak. Hal ini dibuktikan dengan hasil uji chisquare yaitu didapatkan nilai signifikansi kurang dari 0,05 $(\mathrm{p}<0,05)$. Pada tabel menunjukkan bahwa responden dalam penelitian ini mayoritas berusia 20-35 tahun, berpendidikan tinggi, tidak bekerja, tingkat penghasilannya kurang dari UMR, dan memiliki anak lebih dari satu. 


\section{Analisis Bivariat}

Analisis bivariat yang digunakan pada penelitian ini memakai uji koefisien kontingensi untuk mengetahui apakah terdapat hubungan atau tidak dalam penelitian ini.

Tabel 2. Tabulasi silang tingkat pengetahuan ibu tentang ASI terhadap Pemberian ASI eksklusif

\begin{tabular}{lcccccc}
\hline \multirow{2}{*}{ Pengetahuan } & \multicolumn{2}{c}{ ASI Eksklusif } & \multicolumn{2}{c}{ Tidak ASI Eksklusif } & Total & $\boldsymbol{P}_{\text {value }}$ \\
\cline { 2 - 7 } Kurang & Jumlah (n) & Presentase $(\%)$ & Jumlah (n) & Presentase $(\%)$ & & \\
Cukup & 1 & $50,0 \%$ & 1 & $50,0 \%$ & 2 & \\
Baik & 8 & $34,8 \% \%$ & 15 & $65,2 \%$ & 23 & 0,251 \\
Total & 42 & $54,5 \%$ & 35 & $45,5 \%$ & 77 & \\
\hline
\end{tabular}

Hubungan antara tingkat pengetahuan ibu tentang ASI dengan pemberian ASI Eksklusif dilihat dengan menggunakan uji koefisien kontingensi. Berdasarkan tabel 2 didapatkan bahwa tidak terdapat hubungan antara tingkat pengetahuan ibu tentang ASI dengan pemberian ASI Eksklusif di puskesmas kenjeran karena nilai $\mathrm{p}>0,05$ yaitu $\mathrm{p}=$ 0,251 .

\section{Kategori pengetahuan berdasarkan peta pertanyaan}

Salah satu tujuan penelitian yaitu mengetahui faktor pengetahuan yang paling kuat pada pemberian ASI eksklusif di penelitian ini. Hal ini dilihat dari kategori pengetahuan dalam peta pertanyaan kuesioner dan diolah dengan menggunakan uji koefisein kontingensi. Dalam penelitian ini kategori pengetahuan dibagi menjadi 11 kategori pengetahuan dan hanya 8 kategori yang diolah karena terdapat beberapa pertanyaan yang tidak valid.

Berdasarkan tabel 3 dari hasil uji statistik koefisien kontingensi didapatkan nilai signifikansinya 0,014 $(\mathrm{p}<0,05)$. Maka dapat disimpulkan bahwa terdapat hubungan yang signifikan antara pengetahuan tentang pengertian ASI dengan pemberian ASI eksklusif.

Tabel 3. Pengetahuan tentang pengertian ASI

\begin{tabular}{lcccccc}
\hline \multirow{2}{*}{ Pengetahuan } & \multicolumn{2}{c}{ ASI Eksklusif } & \multicolumn{2}{c}{ Tidak ASI Eksklusif } & \multirow{2}{*}{ Total } & \multirow{2}{*}{$\boldsymbol{P}_{\text {value }}$} \\
\cline { 2 - 5 } & Jumlah (n) & Persentase $(\%)$ & Jumlah (n) & Persentase $(\%)$ & & \\
\cline { 1 - 4 } Kurang & 1 & $100 \%$ & 0 & $0,0 \%$ & 1 & \\
Cukup & 6 & $25,0 \%$ & 18 & $75,0 \%$ & 24 & 0,014 \\
Baik & 44 & $57,1 \%$ & 33 & $42,9 \%$ & 77 & \\
Total & 51 & $50,0 \%$ & 51 & $50,0 \%$ & 102 & \\
\hline
\end{tabular}


Tabel 4. Pengetahuan tentang manfaat pemberian ASI bagi ibu

\begin{tabular}{lcccccc}
\hline \multirow{2}{*}{ Pengetahuan } & \multicolumn{2}{c}{ ASI Eksklusif } & \multicolumn{2}{c}{ Tidak ASI Eksklusif } & \multirow{2}{*}{ Total } & \multirow{2}{*}{$\boldsymbol{P}_{\text {value }}$} \\
\cline { 2 - 5 } Kurang & Jumlah (n) & Persentase (\%) & Jumlah (n) & Persentase (\%) & & \\
Cukup & 1 & $20,0 \%$ & 4 & $80,0 \%$ & 5 & \\
Baik & 37 & $54,4 \%$ & 31 & $45,6 \%$ & 68 & 0,267 \\
Total & 13 & $44,8 \%$ & 16 & $55,2 \%$ & 29 & \\
\hline
\end{tabular}

Berdasarkan tabel 4 hasil uji statistik koefisien terdapat hubungan yang signifikan antara kontingensi didapatkan nilai signifikansinya 0,267 pengetahuan mengenai manfaat pemberian ASI (p>0,05). Maka dapat disimpulkan bahwa tidak bagi ibu dengan pemberian ASI eksklusif.

Tabel 5. Pengetahuan tentang perbandingan manfaat ASI dengan susu formula

\begin{tabular}{lcccccc}
\hline \multirow{2}{*}{ Pengetahuan } & \multicolumn{2}{c}{ ASI Eksklusif } & \multicolumn{2}{c}{ Tidak ASI Eksklusif } & \multirow{2}{*}{ Total } & \multirow{2}{*}{$\boldsymbol{P}_{\text {value }}$} \\
\cline { 2 - 5 } & Jumlah (n) & Persentase (\%) & Jumlah (n) & Persentase (\%) & & \\
\cline { 1 - 5 } Kurang & 0 & $0,0 \%$ & 0 & $0,0 \%$ & 0 & \\
Cukup & 3 & $20,0 \%$ & 12 & $80,0 \%$ & 15 & \multirow{2}{*}{0,012} \\
Baik & 48 & $55,2 \%$ & 39 & $44,8 \%$ & 87 & \\
Total & 51 & $50,0 \%$ & 51 & $50,0 \%$ & 102 & \\
\hline
\end{tabular}

Berdasarkan tabel 5 hasil uji statistik koefisien kontingensi didapatkan nilai signifikansinya 0,012 $(\mathrm{p}<0,05)$. Maka dapat disimpulkan bahwa terdapat hubungan yang signifikan antara pengetahuan tentang perbandingan manfaat ASI dengan susu formula dengan pemberian ASI eksklusif.

Tabel 6. Pengetahuan tentang kandungan nutrisi dalam ASI

\begin{tabular}{lcccccc}
\hline \multirow{2}{*}{ Pengetahuan } & \multicolumn{2}{c}{ ASI Eksklusif } & \multicolumn{2}{c}{ Tidak ASI Eksklusif } & \multirow{2}{*}{ Total } & \multirow{2}{*}{$\boldsymbol{P}_{\text {value }}$} \\
\cline { 2 - 5 } & Jumlah (n) & Persentase (\%) & Jumlah (n) & Persentase (\%) & & \\
\cline { 1 - 4 } Kurang & 3 & $60,0 \%$ & 2 & $40,0 \%$ & 5 & \\
Cukup & 12 & $37,5 \%$ & 20 & $62,5 \%$ & 32 & 0,228 \\
Baik & 36 & $55,4 \%$ & 29 & $44,6 \%$ & 65 & \\
Total & 51 & $50,0 \%$ & 51 & $50,0 \%$ & 102 & \\
\hline
\end{tabular}

Tabel 6 menunjukkan hasil uji statistik koefisien kontingensi didapatkan nilai signifikansinya 0,228 ( $>>0,05)$. Maka dapat disimpulkan bahwa tidak terdapat hubungan yang signifikan antara pengetahuan tentang kandungan nutrisi dalam ASI dengan pemberian ASI eksklusif. 
Tabel 7. Pengetahuan tentang perbandingan kandungan nutrisi ASI dan susu formula

\begin{tabular}{lcccccc}
\hline \multirow{2}{*}{ Pengetahuan } & \multicolumn{2}{c}{ ASI Eksklusif } & \multicolumn{2}{c}{ Tidak ASI Eksklusif } & \multirow{2}{*}{ Total } & \multirow{2}{*}{$\boldsymbol{P}_{\text {value }}$} \\
\cline { 2 - 5 } Kurang & Jumlah (n) & Persentase $(\%)$ & Jumlah (n) & Persentase (\%) & & \\
Cukup & 0 & $0,0 \%$ & 2 & $100,0 \%$ & 2 & \\
Baik & 7 & $35,0 \%$ & 13 & $65,0 \%$ & 20 & 0,100 \\
Total & 44 & $55,0 \%$ & 36 & $45,0 \%$ & 80 & \\
\hline
\end{tabular}

Pada tabel 7 hasil uji statistik koefisien kontingensi didapatkan nilai signifikansinya $0,100 \quad(p>0,05)$. Maka dapat disimpulkan bahwa tidak terdapat hubungan yang signifikan antara pengetahuan tentang perbandingan kandungan nutrisi ASI dan susu formula dengan pemberian ASI eksklusif.
Berdasarkan tabel 8 hasil uji statistik koefisien kontingensi didapatkan nilai signifikansinya 0,171 ( $>00,05)$. Maka dapat disimpulkan bahwa tidak terdapat hubungan yang signifikan antara pengetahuan tentang inisiasi menyusui dini dengan pemberian ASI eksklusif.

Tabel 8. Pengetahuan tentang inisiasi menyusui dini

\begin{tabular}{lcccccc}
\hline \multirow{2}{*}{ Pengetahuan } & \multicolumn{2}{c}{ ASI Eksklusif } & \multicolumn{2}{c}{ Tidak ASI Eksklusif } & \multirow{2}{*}{ Total } & \multirow{2}{*}{$\boldsymbol{P}_{\text {value }}$} \\
\cline { 2 - 5 } & Jumlah (n) & Persentase $(\%)$ & Jumlah (n) & Persentase (\%) & & \\
\cline { 1 - 4 } Kurang & 4 & $44,4 \%$ & 5 & $55,6 \%$ & 9 & \\
Cukup & 11 & $36,7 \%$ & 19 & $63,3 \%$ & 30 & \multirow{2}{*}{0,171} \\
Baik & 36 & $57,1 \%$ & 27 & $42,9 \%$ & 63 & \\
Total & 51 & $50,0 \%$ & 51 & $50,0 \%$ & 102 & \\
\hline
\end{tabular}

Tabel 9 menunjukkan hasil uji statistik koefisien terdapat hubungan yang signifikan antara kontingensi didapatkan nilai signifikansinya 0,426 pengetahuan tentang masalah menyusui pada ( $>00,05)$. Maka dapat disimpulkan bahwa tidak putting lecet dengan pemberian ASI eksklusif.

Tabel 9. Pengetahuan tentang masalah menyusui pada puting lecet

\begin{tabular}{lcccccc}
\hline \multirow{2}{*}{ Pengetahuan } & \multicolumn{2}{c}{ ASI Eksklusif } & \multicolumn{2}{c}{ Tidak ASI Eksklusif } & & \\
\cline { 2 - 4 } & Jumlah (n) & $\begin{array}{r}\text { Persentase } \\
(\%)\end{array}$ & Jumlah (n) & $\begin{array}{r}\text { Persentase } \\
(\%)\end{array}$ & Totall & $P_{\text {value }}$ \\
\cline { 2 - 5 } Kurang & 9 & $45,0 \%$ & 11 & $55,0 \%$ & 9 & \\
Cukup & 24 & $46,2 \%$ & 28 & $53,8 \%$ & 30 & 0,426 \\
Baik & 18 & $60,0 \%$ & 12 & $40,0 \%$ & 63 & \\
Total & 51 & $50,0 \%$ & 51 & $50,0 \%$ & 102 & \\
\hline
\end{tabular}


Tabel 10. Pengetahuan tentang cara pemberian ASI

\begin{tabular}{lcccccc}
\hline \multirow{2}{*}{ Pengetahuan } & \multicolumn{2}{c}{ ASI Eksklusif } & \multicolumn{2}{c}{ Tidak ASI Eksklusif } & \multirow{2}{*}{ Total } & \multirow{2}{*}{$\boldsymbol{P}_{\text {value }}$} \\
\cline { 2 - 5 } Kurang & Jumlah (n) & Persentase $(\%)$ & Jumlah (n) & Persentase (\%) & & \\
Cukup & 7 & $50,0 \%$ & 7 & $50,0 \%$ & 14 & \\
Baik & 20 & $47,6 \%$ & 22 & $52,4 \%$ & 42 & 0,913 \\
Total & 24 & $52,2 \%$ & 22 & $47,8 \%$ & 46 & \\
\hline
\end{tabular}

Dari tabel 10 hasil uji statistik koefisien kontingensi didapatkan nilai signifikansinya 0,913 ( $>0$,05). Maka dapat disimpulkan bahwa tidak

\section{PEMBAHASAN}

Hasil penelitian hubungan antara tingkat pengetahuan ibu tentang ASI dengan pemberian ASI eksklusif di puskesmas kenjeran menunjukkan sebagian besar responden memiliki tingkat pengetahuan yang baik. Berdasarkan analisis bivariat dengan menggunakan uji koefisien kontingensi, didapatkan bahwa tidak terdapat hubungan antara tingkat pengetahuan ibu tentang ASI dengan pemberian ASI eksklusif di puskesmas kenjeran. Hal ini dapat terjadi karena ibu yang menyusui belum memahami dan mengamplikasikan apa yang mereka ketahui ${ }^{(8)}$. Praktik pemberian ASI eksklusif ini sendiri lebih ditetntukan oleh keinginan pribadi dan manajemen laktasi oleh petugas kesehatan pada saat pertolongan persalinan di tempat pelayanan kesehatan $^{(9)}$. Hasil penelitian ini bertolak belakang dengan penelitian rachmaniah (2014) yang menyatakan bahwa terdapat hubungan antara tingkat pengetahuan ibu dengan pemberian ASI eksklusif dan mengatakan bahwa ibu yang terdapat hubungan yang signifikan antara pengetahuan tentang cara pemberian ASI dengan pemberian ASI eksklusif.

berpengetahuan rendah cenderung tidak memberikan ASI eksklusif sedangkan ibu yang berpengetahuan tinggi semakin tinggi pula keinginan untuk memberikan ASI eksklusif( ${ }^{(6)}$. Meskipun dalam penelitian ini pengetahuan ibu tidak berhubungan dengan pemberian ASI eksklusif, tetapi secara spesifik berdasarkan beberapa kategori pengetahuan dalam peta pertanyaan kuesioner terdapat 2 kategori pengetahuan yang paling mempengaruhi pemberian ASI, yaitu: pengertian ASI, dan perbandingan manfaat ASI dengan susu formula.

\section{KESIMPULAN}

Sebagian besar responden memiliki tingkat pengetahuan yang baik tentang ASI. Tidak didapatkan hubungan antara tingkat pengetahuan ibu tentang ASI dengan pemberian ASI eksklusif di Puskesmas Kenjeran. Faktor pengetahuan yang paling kuat pada pemberian ASI eksklusif. dalam penelitian ini yaitu pengertian ASI dan perbandingan manfaat ASI dengan susu formula. 


\section{DAFTAR PUSTAKA}

1. Kementerian Kesehatan Republik Indonesia. Situasi dan Analisis ASI eksklusisf . 2014. p. 1-6. Available from: https://www.kemkes.go.id/article/view/1 4010200010/situasi-dan-analisis-asieksklusif.html

2. Kementerian Kesehatan Republik Indonesia. Indonesia health profile at 2018. 2019. Available from: https://pusdatin.kemkes.go.id/resources/ download/pusdatin/profil-kesehatanindonesia/PROFIL_KESEHATAN_201 8_1.pdf

3. Kusumaningrum T, Lestari CP, Sulistyono A. Factor Analysis about Exclusive Breastfeeding Achievement Level among Mothers who Provide Breastmilk to their Children. Jurnal Ners. 2010;5(1):55-61. Available from: https://ejournal.unair.ac.id/JNERS/article/downlo $\mathrm{ad} / 3924 / 2654$

4. Qoyyimah AU, Rohmawati W. Dampak pemberian ASI eksklusif terhadap kejadian sakit pada bayi usia 6-12 bulan di kabupaten Klaten. 5th Urecol Proceeding. 2017;16116. Available from: http://lpp.uad.ac.id/wpcontent/uploads/2017/05/URECOL_A NNA-UQ_STIKES-MUKLA.pdf

5. Qomariyah N. ARTIKEL PENELITIAN PENGETAHUAN, SIKAP, DAN PRAKTIK DALAM PEMBERIAN ASI
EKSKLUSIF DI WILAYAH KERJA PUSKESMAS REMBANG 2 DAN PUSKESMAS SARANG (Studi Kualitatif pada Ibu Menyusui dengaan Usia Bayi 0-6 Bulan Tahun 2015). Jurnal Kesehat Masyarakat. 2016;4(1):2356-3346. Available from: http://ejournals1.undip.ac.id/index.php/jkm

6. Rachmaniah N. Hubungan Tingkat Pengetahuan Ibu Tentang ASI dengan Tindakan ASI Eksklusif. Naskah Publikasi. 2014. Available from: http://eprints.ums.ac.id/29462/12/NAS KAH_PUBLIKASI.pdf

7. Nurkhayati A. HUBUNGAN ANTARA PENGETAHUAN IBU TENTANG ASI EKSKLUSIF DENGAN MOTIVASI PEMBERIAN ASI EKSKLUSIF. Naskah Publikasi. Universitas Muhammadiyah Surakarta; 2014. Available from: http://eprints.ums.ac.id/30536/17/02._N askah_Publikasi.pdf

8. Alimuddin NMN, Kapantov NH, Kawengian SE. Hubungan antara Pengetahuan dan Sikap Ibu dengan Pemberian ASI Eksklusif pada Bayi Berusia 6-12 Bulan di Wilayah Kerja Puskesmas Bailang Kota Manado. Kesehatan Masyarakat. 2017;6(4):1-7. Available from: https://ejournal.unsrat.ac.id/index.php/k esmas/article/view/23088/22784

9. Sartono A, Utaminingrum $\mathrm{H}$. Hubungan 
Pengetahuan Ibu, Pendidikan Ibu Dan

Dukungan Suami Dengan Praktek

Pemberian Asi Eksklusif di Kelurahan

Muktiharjo Kidul Kecamatan Telogosari

Kota Semarang. Gizi Universitas

Muhamadiyah Semarang [Internet].

2012;1(1):1-9. Available from:

https://jurnal.unimus.ac.id/index.php/jgi

zi/article/download/565/615 